Case Reports
in Dermatology
Case Rep Dermatol 2020;12:114-118

DOI: $10.1159 / 000507915$

Published online: May 18, 2020
(C) 2020 The Author(s)

Published by S. Karger AG, Basel www.karger.com/cde

This article is licensed under the Creative Commons Attribution-NonCommercial 4.0 International License (CC BY-NC) (http://www.karger.com/Services/OpenAccessLicense). Usage and distribution for commercial purposes requires written permission.

\title{
A Case of Pincer Nail Successfully Treated with Tazarotene $0.1 \%$ Gel
}

\author{
Laura Vollono Ester Del Duca Sara Mazzilli Luca Bianchi \\ Terenzio Cosio Caterina Lanna Elena Campione
}

Dermatology Unit, Department of "Medicina dei Sistemi," University of Rome Tor Vergata, Rome, Italy

\section{Keywords}

Pincer nails $\cdot$ Conservative treatments $\cdot$ Topical tazarotene $\cdot$ Nail diseases

\begin{abstract}
Pincer nail is a common condition characterized by excessive transverse nail curvature, progressively pinching the nail bed distally, resulting in cosmetic discomfort, pain and functional limitation. Treatment is difficult and often unsatisfactory. Surgical treatment performed by experienced physicians provides good outcomes. However, patients usually hesitate to undergo invasive procedures, preferring conservative treatments. Unfortunately, these mainly offer only temporary relief and recurrence rate is high. Topical tazarotene has been used in several nail conditions, but its potential remains not fully elucidated. We herewith present a case of pincer nails in a 35 -year-old woman successfully treated with tazarotene $0.1 \%$ gel applied topically twice a day for 3 months who did not experience recurrence at 1-year follow-up. At 1-year follow-up, no recurrence has been observed. To our knowledge, this is the first case of pincer nails successfully treated with tazarotene $0.1 \%$ gel. With our report, we suggest topical tazarotene as a novel, effective conservative treatment of milder cases of this common, albeit disturbing condition. Although our report may not be sufficient to generalize the results, it paves the way for larger studies investigating the potential of this fast, noninvasive therapeutic agent.

(C) 2020 The Author(s)

Published by S. Karger AG, Basel
\end{abstract}




\section{Case Reports in Dermatology}

Case Rep Dermatol 2020;12:114-118

DOI: 10.1159/000507915

C 2020 The Author(s). Published by S. Karger AG, Basel www.karger.com/cde

Vollono et al.: Tazarotene Gel as a Novel Therapeutic Option for Pincer Nails

\section{Introduction}

Pincer nails is a quite common, mostly acquired condition in which the nails are transversally hypercurved, with their lateral edges traumatizing the lateral folds causing pain [1]. Exact prevalence is difficult to determine as these patients may refer to different professionals, such as podiatrists, orthopedics, surgeons, general practitioners, dermatologists, or rely on self-medication.

Although surgical treatment performed by experienced physicians provides satisfying results, many patients refuse invasive procedures, preferring conservative treatments. However, no standard method has been established to date, and such treatments seem to offer only temporary relief, hence recurrence rate is high. Thus, other therapeutic strategies are necessary. Tazarotene $0.1 \%$ formulations have been used with good results in several nail conditions, such as nail psoriasis, onychomycosis, and brittle nail syndrome [2-4].

\section{Case Presentation}

A 35-year-old female presented for evaluation of a nail deformity of the left great toenail, which appeared many years prior, progressively worsening over time. The patient complained increasing pain and limitation to wearing shoes or walking as the deformity progressed. She was otherwise healthy and had no family history of a similar lesion. Dermatological examination revealed a dystrophic left nail with prominent right axial curvature that caused compression of the distal nail bed (Fig. 1a). Radiographic examination was unremarkable. Routine fungal culture ruled out onychomycosis. Since the patient refused any surgical option, conservative treatment using tazarotene $0.1 \%$ gel twice a day was prescribed. Five months later, a significant reduction of the transverse nail overcurvature and a broadening of the nail plate was observed (Fig. 1b). The patient did not complain any adverse events besides mild erythema of periungual tissues. She reported significant improvement of her symptoms, not requiring further application. At 1-year follow-up, no recurrence was observed.

\section{Discussion}

Pincer nail is a condition characterized by excessive transverse nail curvature, progressively pinching the nail bed distally. It is quite common in the toenails of adults, while they are rare in the fingernails, where they are related to abnormalities of the distal phalanx (exostosis or arthritis). The great toes are the most commonly affected [1]. 3 clinical types have been identified: (1) the common type (trumpet nail), (2) the tile-shaped nail and (3) the plicated nail. In the common type, overcurvature increases along the axis from proximal to distal, shrinking in its transverse diameter and pinching the nail bed. The nail plate is markedly thickened, leading to difficulty to cut the nail. Cosmetic discomfort, increasing pain and functional limitation urge patients to seek medical attention. Dermatologists, orthopedics, and plastic surgeons are usually consulted. Most cases are acquired. Rarely, an underlying tumor such as exostosis, implantation cyst, or myxoid pseudocyst may exist, thus X-ray is advisable. The pathogenesis seems to be related to deviation and enlargement of the distal phalanx to which the matrix is firmly bound by ligament-like collagen with flattening of the adherent nail, resulting in increased distal curvature $[1,5]$. Therapeutic approaches vary according to the severity and type of overcurvature, possible risk factors, previous unsuccessful treatment and 


\section{Case Reports in Dermatology}

Case Rep Dermatol 2020;12:114-118 DOI: 10.1159/000507915

(c) 2020 www.karger.com/cde

Vollono et al.: Tazarotene Gel as a Novel Therapeutic Option for Pincer Nails

personal preferences. Surgical nail avulsion has been reported to dramatically worsen the condition, thus it is not recommended. Permanent removal of the lateral matrix horns with eventual expansion of the pinched nail bed performed by experienced physicians leads to resolution of the condition in $>80 \%$ of the cases $[1,6]$. However, only a minority of surgeons owns the experience and training required to perform such procedures. Patients usually hesitate to undergo surgery, preferring conservative treatments. In mild cases, thinning of the central portion of the nail plate may alleviate the pain by increasing the nail plate's pliability. Noninvasive techniques such as the use of elastic or steel braces (orthonyx) showed good results [7, 8]. However, about 6-12 months of treatments are required, and a very high rate of recurrence is observed. Tazarotene is a synthetic third-generation retinoid deriving from vitamin A. It has been used in a variety of dermatological conditions, such as acne or non-melanoma skin tumors. As to nails, it has been used with good results for the treatment of psoriasis, onychomycosis, and brittle nail syndrome [2-4]. Its effectiveness in such conditions probably lies in its capability to modulate keratinocytic proliferation, exerted by transactivation of nuclear retinoic acid receptors, reduction in the excessive V-Akt murine thymoma viral oncogene homolog 1 activation-supporting cell growth and reduction of hyperproliferation-associated keratins 6 and 16 [9-11]. Tazarotene may thus exert its therapeutic effect by normalizing keratinocytic proliferation and subsequently limiting acanthosis of the nail bed epithelium responsible for the thickened, hard-to-cut nails. The treatment is considered safe and free of adverse events, although 1 case of pyogenic granuloma with the use of tazarotene gel for nail psoriasis has been reported [12]. Unlike previously published reports regarding conservative treatment of pincer nails, our patient achieved significant results after only 3 months, in the absence of recurrence at 1-year follow-up. Although our sample is too small to generalize the results, we hope our report may pave to way for larger studies investigating the potential of this fast, noninvasive therapeutic agent.

\section{Acknowledgements}

The authors wish to thank Dr. Gabriele Mazzitelli for his support in providing the scientific material needed for this paper.

\section{Statement of Ethics}

Written informed consent to publish this case (including images) was obtained from the patient. The research was conducted ethically in accordance with the World Medical Association Declaration of Helsinki.

\section{Disclosure Statement}

The authors have no conflicts of interest to declare.

\section{Funding Sources}

The authors did not receive any funding. 


\section{Case Reports in Dermatology}

\begin{tabular}{l|l}
\hline DOI: $10.1159 / 000507915$ & (c) 2020 The Author(s). Published by S. Karger AG, Basel
\end{tabular} www.karger.com/cde

Vollono et al.: Tazarotene Gel as a Novel Therapeutic Option for Pincer Nails

\section{Author Contributions}

Laura Vollono: conception and design, interpretation of the data, drafting, final approval. Ester Del Duca: acquisition and interpretation of the data, drafting, final approval.

Sara Mazzilli, Luca Bianchi: acquisition, analysis, and interpretation of the data; revision; final approval.

Terenzio Cosio, Caterina Lanna: revision, final approval.

Campione Elena: conception and design, acquisition and interpretation of data, revision, final approval.

All authors agree to be accountable for all aspects of the work in ensuring that questions related to the accuracy or integrity of any part of the work are appropriately investigated and resolved.

\section{References}

1 Baran R, Haneke E, Richert B. Pincer nails: definition and surgical treatment. Dermatol Surg. 2001 Mar;27(3):261-6.

2 Campione E, Paternò EJ, Costanza G, Diluvio L, Carboni I, Marino D, et al. Tazarotene as alternative topical treatment for onychomycosis. Drug Des Devel Ther. 2015 Feb;9:879-86.

3 Sherber NS, Hoch AM, Coppola CA, Carter EL, Chang HL, Barsanti FR, et al. Efficacy and safety study of tazarotene cream 0.1\% for the treatment of brittle nail syndrome. Cutis. $2011 \mathrm{Feb} ; 87(2): 96-103$.

4 Diluvio L, Campione E, Paternò EJ, Mordenti C, El Hachem M, Chimenti S. Childhood nail psoriasis: a useful treatment with tazarotene 0.05\%. Pediatr Dermatol. 2007 May-Jun;24(3):332-3.

5 Cornelius CE 3rd, Shelley WB. Pincer nail syndrome. Arch Surg. 1968 Feb;96(2):321-2.

6 Vaccari S, Dika E, Balestri R, Rech G, Piraccini BM, Fanti PA. Partial excision of matrix and phenolic ablation for the treatment of ingrowing toenail: a 36-month follow-up of 197 treated patients. Dermatol Surg. 2010 Aug;36(8):1288-93.

7 Effendy I, Ossowski B, Happle R. Zangennagel. Konservative Korrektur durch Aufkleben einer Kunststoffspange. Hautarzt. 1993 Dec;44(12):800-2.

8 Fraser AR. Orthonyx: theory and practice. Br J Chirop. 1967;32:229-32.

9 Thacher SM, Vasudevan J, Chandraratna RA. Therapeutic applications for ligands of retinoid receptors. Curr Pharm Des. 2000 Jan;6(1):25-58.

10 Cervelli V, Scioli MG, Gentile P, Doldo E, Bonanno E, Spagnoli LG, et al. Platelet-rich plasma greatly potentiates insulin-induced adipogenic differentiation of human adipose-derived stem cells through a serine/threonine kinase Akt-dependent mechanism and promotes clinical fat graft maintenance. Stem Cells Transl Med. 2012 Mar;1(3):206-20.

11 Bianchi L, Orlandi A, Campione E, Angeloni C, Costanzo A, Spagnoli LG, et al. Topical treatment of basal cell carcinoma with tazarotene: a clinicopathological study on a large series of cases. Br J Dermatol. 2004 Jul;151(1):148-56.

12 Piraccini BM, Venturi M, Patrizi A. Periungual pyogenic granulomas due to topical tazarotene for nail psoriasis. G Ital Dermatol Venereol. 2014 Jun;149(3):363-6. 


\section{Case Reports in Dermatology}

(c) 2020 The Author(s). Published by S. Karger AG, Basel www.karger.com/cde

Vollono et al.: Tazarotene Gel as a Novel Therapeutic Option for Pincer Nails

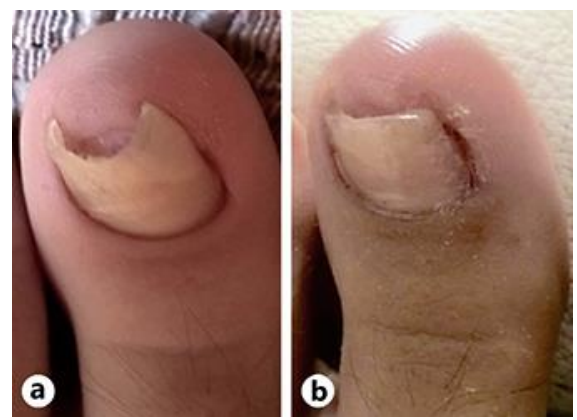

Fig. 1. a Dystrophic, hypercurved left toenail. b Improvement of signs and symptoms after 5 months of treatment. 